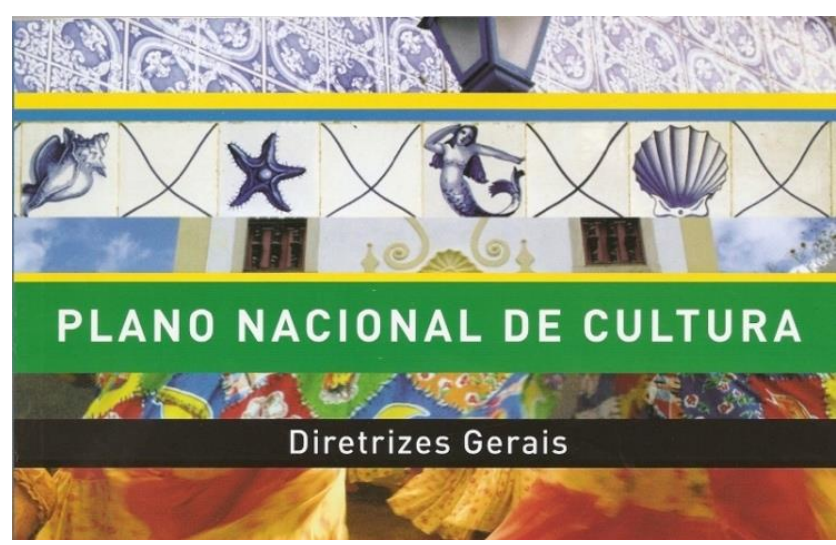

\title{
Ler a cultura hoje: a construção do consenso nas políticas culturais do Estado brasileiro ${ }^{1}$
}

\author{
Understanding the culture today: \\ the construction of the consensus on cultural policies of Brazilian state
}

Felipe Augusto Santana do Nascimento ${ }^{2}$

\section{Resumo:}

Este trabalho, situado na Análise de Discurso, tem como objetivos discutir a noção de cultura e compreender a produção do consenso nas políticas públicas de cultura do Estado brasileiro na contemporaneidade. Ao analisar sequências recortadas do site do Ministério da Cultura (MinC), mais especificamente do Plano Nacional de Cultura (PNC), discuto como as políticas de democratização e democracia cultural aparecem como consenso para a inclusão cultural, o respeito à diversidade cultural e a difusão do "vínculo" social. Assim, diferentemente de um "vínculo" construído apenas pelo "consenso étnico-cultural", o que observo é o funcionamento da construção do consenso pela democracia, que se ancora no jurídico: o direito de todos à cultura. Palavras-chave: Análise de Discurso. Consenso. Cultura. Políticas Culturais.

\begin{abstract}
:
The present work, situated in the Discourse Analysis, aims to discuss the notion of culture and to understand the production of consensus on cultural public policies of contemporary Brazilian state. By analyzing cropped sequences available at the Culture Ministry (Ministério da Cultura, MinC) website, specifically the National Plan of Culture (Plano Nacional de Cultura, PNC), I discuss how both the democratization policies and the cultural democracy are taken as consensus to the cultural inclusion, to the respect to the cultural diversity and to the diffusion of social "bonding". Thereby, differently from the "bonding" constructed only through "ethnical-cultural consensus", what I observe is the construction of consensus for democracy working mechanism, which is supported by the juridical: The right of all to culture.
\end{abstract}

Keywords: Discourse Analysis. Consensus. Culture. Cultural Policies.

\footnotetext{
${ }^{1}$ O título Ler a cultura hoje faz referência ao texto de Michel Pêcheux (2010), Ler o arquivo hoje.

${ }^{2}$ Doutorando em Linguística pelo Programa de Pós-graduação em Linguística da Universidade Estadual de Campinas (Unicamp). Bolsista CNPq. Endereço: Rua Sérgio Buarque de Holanda, no 571. Campinas - SP - Brasil. CEP 13083-859. E-mail: felipe.augustus@ hotmail.com
} 


\title{
1. Introdução
}

A palavra "cultura" funciona contraditoriamente pelo e no equívoco. É com esta afirmação que começo este trabalho. Nas mais diferentes áreas do conhecimento, tornouse lugar comum dizer que é inegável a dificuldade de se definir o que é cultura, já que a noção de cultura vem sendo submetida a disputas de sentidos e, ao mesmo tempo, a um apagamento pela forte difusão e "democratização" pela qual vem passando essa palavra. Isto porque, ao se definir o que é cultura, produzem-se uma totalização (comum a qualquer definição) e uma dilatação dos seus sentidos, a fim de dar conta do que seria a cultura. Dessa forma, ao mesmo tempo em que observamos uma proliferação dos sentidos de cultura $^{3}$, percebemos uma tentativa de cerceamento dessa palavra, principalmente por meio da disciplinarização a que tal palavra está submetida. Tal disciplinarização, em certa medida, interessa às Políticas Culturais, uma vez que as atuais políticas de Estado buscam dialogar com as mais diversas disciplinas, a fim de definir o seu foco de atuação ${ }^{4}$. Prova disso, foi a declaração do ex-Ministro da Cultura, Juca Ferreira, na posse do Pleno do Conselho Nacional de Política Cultural (CNPC), em 16 de dezembro de 2015.

\begin{abstract}
Então, nós democratizamos o conceito de cultura, não só no sentido antropológico, social, nós conseguimos sair de uma identidade reducionista onde cultura e arte é a mesma coisa e usamos todo o legado da antropologia e de outras ciências e passamos a tratar todo o mundo simbólico como parte da cultura, valores, fazeres, saberes, tradições. Não inventamos nada, mas o Estado brasileiro frequentemente é o último a saber e nós tivemos que trazer para as políticas culturais essa noção mais complexa de cultura. $(16 / 12 / 2015 \text {, grifo meu })^{5}$
\end{abstract}

A partir de seu lugar de Ministro da Cultura, são enfatizadas a democratização e a ampliação do conceito de cultura como fundamentais para as políticas públicas de cultura hoje. Ao contrário de noções anteriores, que igualavam cultura à arte, passa-se a incluir como cultura todo o mundo simbólico, o que torna a noção ainda mais complexa. Embora reconhecendo a complexidade da noção, é válido salientar a homogeneização

\footnotetext{
${ }^{3}$ Apresentei algumas considerações sobre o verbete "cultura" em dicionários de língua portuguesa no V Encontro Nacional de Estudos da Linguagem e IV Encontro Internacional de Estudos da Linguagem (ENELIN), na Univás em Pouso Alegre - Minas Gerais. O texto completo poderá ser lido nos Anais do evento (NASCIMENTO, 2016).

${ }^{4}$ Este texto começou a ser pensado no período do afastamento da Presidenta Dilma Rousseff (12/05/2016). Após a sua destituição, o foco das políticas culturais brasileira tornou-se incerto devido aos sucessivos desmontes que o Ministério da Cultura foi submetido.

5 Disponível em: http://www.cultura.gov.br/discursos/-/asset_publisher/DmSRak0YtQfY/content/juca$\%$ E2\% $80 \% 9$ Ctratamos-todo-o-mundo-simbolico-como-parte-da-cultura\%E2\%80\%9D/10883
} 
construída por meio do pronome indefinido "todo" em duas situações: "todo o legado da antropologia e das outras ciências" e "todo o mundo simbólico". Produzem-se, com isso, um efeito de totalidade sobre a definição de cultura nas mais diversas ciências e a ilusão de que os diferentes elementos do mundo simbólico fazem parte, igualmente, do que é considerado cultura. Por outro lado, apagam-se a heterogeneidade de dizeres sobre a noção de cultura que está inserida na Antropologia e em outras ciências, a impossibilidade de apreender todo o mundo simbólico e o fato de que definir esse ou aquele elemento como cultural é uma decisão política.

Além das noções de simbólico, política e cultural, é preciso se questionar sobre o que seria a democratização do conceito de cultura e o que se está sendo compreendido por cultura nas políticas culturais. Embora haja diversas tipologias sobre os tipos de políticas culturais adotadas pelos Estados modernos, cada uma se ancorando em uma noção de cultura, destaco, neste trabalho, "as políticas de difusão e produção cultural" mais especificamente às "políticas de democratização da cultura" (que permite o acesso igualitário aos bens culturais, sobretudo os bens considerados parte da "cultura erudita") e às políticas de democracia cultural (valorização das mais diversas práticas culturais, principalmente as tidas como populares), que, por meio da palavra "democracia", buscam, de maneira geral, a difusão e o reconhecimento dos bens culturais. Nesse sentido, pergunto-me: que noção mais complexa é essa de cultura que vem sendo utilizada nas políticas culturais do Estado brasileiro? A que filiação teórica-discursiva essa noção se vincula? Como as políticas de democratização e democracia cultural funcionam na construção do consenso sobre o direito à cultura? Essas e outras questões nortearão a nossa reflexão.

\section{A noção de cultura e a Análise de Discurso}

A discussão em torno da noção de cultura na Análise de Discurso (AD) é relativamente recente (MARIANI, 2009) ${ }^{7}$. No entanto, como aponta Leandro-Ferreira (2011, p. 55), é preciso pensar o lugar da cultura na AD não como um lugar vazio,

\footnotetext{
${ }^{6}$ Estou fazendo uso da tipologia proposta por Luciana P. B. Lima, Pablo Ortellado e Valmir Barbosa (2013

${ }^{7}$ Embora seja uma noção relativamente recente, não podemos esquecer que, em Terra à vista (1990), Orlandi discute o funcionamento da palavra "cultura" no discurso sobre os índios e que Carolina Rodríguez, em sua tese de Doutorado (2000), propõe uma discussão sobre a relação entre cultura, Estado e nação para pensar a língua guarani. Tal relação entre cultura, Estado e nação também é trabalhada por esta autora em outros trabalhos (RODRÍGUEZ-ALCALÁ, 2004; 2010).
} 
esquecido ou apagado, mas como um lugar um tanto diluído "para dar espaço maior à relação entre a língua e a história". De certa forma, a noção de cultura sempre esteve presente na Análise de Discurso, mas como uma presença ausente (idem, p. 56) que vem ganhando cada vez mais destaque nos trabalhos em AD no Brasil. Embora a noção venha aparecendo em diferentes trabalhos, ainda não se tem uma definição sobre o que seria cultura para a AD e o lugar que ela deveria ocupar na teoria. Além disso, por se tratar de uma disciplina de entremeio, conforme aponta Orlandi (2012), ainda se discute com qual(is) teoria(s) é possível um diálogo para se pensar essa noção no aparato teórico da AD.

Ainda segundo Leandro-Ferreira (2011, p. 56), a Antropologia poderia contribuir para a (res)significação da noção de cultura na Análise de Discurso. A autora, ao longo de seu texto, provoca-se e questiona os leitores sobre os possíveis diálogos entre as duas teorias. Dentre as aproximações apontadas pela pesquisadora, interessa-me a de determinação. Ao citar um texto de Levi-Strauss, Leandro-Ferreira (p. 63) se questiona se a determinação não seria um dos pontos de encontro da Antropologia com a $\mathrm{AD}$, já que, assim como o sujeito é duplamente determinado na $\mathrm{AD}$ : pelo inconsciente e pela ideologia, a cultura é tomada na Antropologia como elemento de determinação de um grupo social sobre outro. A cultura, assim, para a autora, seria essencial na produção de sentidos como produção de subjetividades, já que o sujeito, a partir de uma posiçãosujeito, inserida em uma formação discursiva, e de um lugar social, inserido em uma formação cultural, produziria sentidos. Haveria, dessa forma, um ritual de assujeitamento da cultura que, sendo sem falhas, "deixaria brechas por onde emergiriam com força as singularidades" (ibidem).

Afasto-me do diálogo proposto por Leandro-Ferreira em relação à Antropologia ${ }^{8}$ e continuo pensando a cultura a partir do próprio aparato da $\mathrm{AD}$, pensando-a no entremeio da ideologia e do inconsciente; e me colocando, para compreender a cultura, "na escuta das circulações cotidianas, tomadas no ordinário do sentido" (PÊCHEUX, 2012, p. 48). Isto implica, ainda segundo Pêcheux, distanciar-se de qualquer ciência régia para que se possa engajar "concretamente maneiras de trabalhar sobre as materialidades discursivas, implicadas em rituais ideológicos, nos discursos filosóficos, em enunciados políticos, nas

\footnotetext{
${ }^{8}$ É preciso questionar à qual Antropologia a autora se refere, visto que a Antropologia é um campo vasto e não coeso. Ao que parece, ela se refere à Antropologia Cultural, mas ainda assim é preciso delimitar que segmento da Antropologia Cultural é possível a AD manter um diálogo, já que muitas vezes determinados segmentos da Antropologia Cultural parte de sujeitos empíricos e negam questões basilares para a AD.
} 
formas culturais e estéticas, através de suas relações com o cotidiano, com o ordinário do sentido" (p. 49, grifo meu $)^{9}$

Assim, dentro do aparato teórico da Análise de Discurso, para pensar a cultura, levo em consideração a sua ambivalência, como aponta Dorneles (2015), ao retomar o trabalho de Bauman ${ }^{10}$. Nesse sentido, a meu ver, a cultura pode ser pensada na ambivalência da ordem e da organização. Tal distinção é feita por Eni Orlandi (2012) para se pensar a língua. Segundo a autora, a ordem é a forma material, o funcionamento da língua, e a organização é a sua forma empírica, abstrata, é o trabalho sobre a língua. Assim, temos, por exemplo, a construção de gramáticas e dicionários como regularizadora da língua.

Em relação à cultura, penso que essa distinção também é necessária, visto que no tocante às políticas culturais estamos falando da organização da cultura, que produz efeitos em sua ordem. As políticas culturais, de modo geral, são o trabalho do Estado sobre a cultura, produzindo um efeito de organização. Tal organização se sustenta sobre outra ambivalência: do sujeito e do objeto. Isto porque se recuperarmos determinado sentido da palavra cultura, temos: cultura como cultivo e como o cultivado. A cultura é, portanto, processo (ato de cultivar, que pressupõe um sujeito) e produto (resultado desse cultivo). Em outras palavras, podemos dizer que a cultura trabalha por meio dessa ambivalência: é processo (tem relação com o sujeito) e é produto (os objetos, os bens culturais). Além disso, a palavra cultura tem uma estreita ligação com a terra, o local, que se materializa nas políticas culturais atualmente pelo investimento às próprias instituições e construções de vínculos dos sujeitos com o espaço no qual eles estão inseridos ${ }^{11}$.

Dessa forma, na esteira do pensamento de Eni Orlandi (2012), não me interessa a organização enquanto tal, mas a sua forma material, sua ordem. Isso, no entanto, não significa que eu negue a importância da organização da cultura, visto que o trabalho do Estado, em busca de uma sistematicidade, é crucial para se pensar a ordem da cultura;

\footnotetext{
${ }^{9}$ Nas referências do artigo de Leandro-Ferreira (2001) consta o texto de Pêcheux (2012) Discurso: estrutura ou acontecimento embora a autora não faça menção a ele no corpo de seu texto. Mariani (2009, p. 47), por sua vez, observa que Pêcheux (2012), nesse mesmo texto, faz alusões lisonjeiras ao termo "cultura", inclusive "quando menciona 'uma promessa de revolução cultural' resultante do encontro de três campos marcados pela "trilogia subversiva Marx-Freud-Saussure"” (p. 47-48). É válido ressaltar que o texto de Pêcheux em questão é resultado de uma conferência, cujo tema era "Marxismo e Interpretação da Cultura: Limites, Fronteiras, Restrições", na Universidade de Illinois Urbana-Champaign, de 8 a 12 de julho de 1983.

${ }^{10}$ Ensaios sobre o conceito de cultura.

${ }^{11}$ Para Rodríguez-Alcalá (2011) “sentidos, sujeitos e espaço estão materialmente ligados”. A c cultura, de alguma forma, atualiza essa relação material.
} 
mas quero dizer que é necessário refletir sobre a organização da cultura para se pensar a ordem da cultura, sua forma material. Daí a necessidade de se pensar as políticas culturais a partir do olhar da Análise de Discurso.

Se o lugar da cultura na Análise de Discurso, como já vem sendo pensado por outros autores (DE NARDI; BALZAN, 2009; LEANDRO-FERREIRA, 2015; VALIM, 2016), pode ser feita na relação entre inconsciente e ideologia, é porque, por ser afetado pelo inconsciente e tomado pela ideologia, o sujeito crê ser o dono e a origem de seu dizer. É o trabalho dessa "dupla estrutura-funcionamento" que permite que o sujeito se identifique com uma cultura e fale a partir desse lugar. A sua cultura, para esse sujeito, muito provavelmente será absoluta, já que o sujeito "enxergará” o mundo a partir de sua cultura, mesmo que ele deseje fazer parte de (se reconheça em) uma cultura outra. A cultura, assim como a língua, precederia o sujeito e, ainda que identificado com uma língua ou cultura outra, a cultura e a língua primeira não deixariam de produzir efeitos nele.

Não podemos esquecer que aqui o Estado tem um papel crucial e as políticas culturais, de maneira geral, são as responsáveis por produzir essa identificação do sujeito com uma cultura. Se, como aponta Rodríguez-Alcalá (2000; 2003; 2004), é a cultura, em certa medida, que passa a desempenhar os mecanismos de identificação dos sujeitos com o Estado, é preciso que compreendamos como se dá esse processo. Se antes sua forma estava identificada com a Igreja (o homem que cultua - cultiva - a Deus), agora ela passa a ser identificada com o Estado (o homem culto, civilizado, cidadão) ${ }^{12}$. Assim, como aponta Descendre, no século XVI, é o domini (sinalizamos o jogo entre domínio e dominação) do Estado sobre o território e sobre os seus indivíduos que começa a pôr em jogo a dimensão pública do poder. É o contato com o outro, a alteridade causada pelo processo de mundialização que é fundamental nessa transição. É por meio da cultura, então, que o Estado, ao dominar um território, passa a individualizar os sujeitos, ao produzir a identificação a uma cultura e submetê-los às suas leis. $\mathrm{O}$ apelo à cultura, nesse

\footnotetext{
${ }^{12}$ Rodríguez-Alcalá (2003, grifo da autora) afirma que “a cultura é materialidade (materialização) da ideologia num espaço-tempo determinado". Em conversa particular, Rodríguez-Alcalá apontou que a cultura pode ser entendida como forma que se materializa nas coisas, a cultura, dessa forma, seria essa forma que os sujeitos reconhecem como evidentes, como pertencentes ao local. Parece-nos que a cultura, embora de forma muito incipiente, apresentava uma forma antes da formação dos Estados nacionais e sua forma estava vinculada ao culto a Deus que, paulatinamente, vai dando espaço ao homem culto, civilizado, cidadão. O trabalho do Estado sobre a cultura (o homem civilizado em oposição ao bárbaro) ganha força, sobretudo, na França por meio dos ideais românticos e da Revolução Francesa. Cultura e nação, dessa forma, chegam a ser igualadas, como se cada nação correspondesse a uma cultura (e uma língua).
} 
sentido, passa a ser a forma de identificação dos sujeitos a um Estado nacional particular (RODRÍGUEZ-ALCALÁ, 2004). Trata-se, portanto, de um trabalho de homogeneização da cultura que, como denomina Esteves $(2011 ; 2014)$, funciona como um efeito-cultura ${ }^{13}$. Tal efeito, também, é resultado de "políticas culturais" do Estado que forjam uma unidade social por meio de valores compartilhados.

Inicia-se, assim, o que podemos chamar de primeiras políticas culturais dos Estados nacionais modernos. Isto porque, conforme apontam Lima et al (2013), tais políticas iniciadas pelo Estado buscavam a construção de uma unidade por meio de uma identidade nacional. Assim, essas políticas culturais de construção de identidade visavam à unidade cultural e, portanto, à identificação dos sujeitos a uma cultura e, consequentemente, a um único Estado nacional. Ao construir um passado comum, por meio de elementos tidos como tradicionais, excluía-se quem não se identificava com esse passado tido como comum.

Embora houvesse, posteriormente, políticas de reconhecimento da diversidade cultural, o que se pode observar é que tal diversidade é incluída nas políticas culturais como necessárias para o reconhecimento das mais diversas comunidades culturais. No entanto, muitas vezes, tais políticas, apesar de buscarem reconhecer a diversidade, baseavam-se nas políticas de identidade, reconhecendo traços comuns entre as diferentes comunidades. Ou seja, ainda que reconhecessem a diversidade presente no Estado nacional, a diversidade era tratada como pequenas unidades que compunham o todo, como se fosse um consenso de que todos que faziam parte dessas comunidades estivessem incluídos nesse passado comum. Isto significa, portanto, que não há uma efetiva mudança política na forma de tratar a cultura, já que era ao consenso étnico-cultural que se recorria para se definir a cultura.

Para mim, se é o Estado que articula o simbólico e o político nas sociedades contemporâneas nacionais (ORLANDI, 2012), seja por meio da identificação à língua (nacional) através dos instrumentos linguísticos (o dicionário e a gramática), seja por

\footnotetext{
${ }^{13}$ Ao retomar o trabalho de Rodríguez-Alcalá (2004) sobre a relação da cultura e os Estados nacionais, Esteves (2014, p. 288) observa que o efeito-cultura produz o pertencimento à nação pela unidade de uma identidade nacional. Esteves (idem, p. 291), dessa forma, baseado nos trabalhos de Orlandi sobre língua fluida e língua imaginária, propõe que entendamos a cultura na relação entre cultura fluida e cultura imaginária. Para o autor, o efeito-cultura e, analogamente, a cultura imaginária "seria aquela normatizada e imposta, que não deixa espaço para a falha e para o equívoco, também impossibilitadora de deslizamentos e com ilusão de homogeneidade/estabilidade. [...] Em oposição a esse efeito imaginário, há uma cultura fluida que foge à regulamentação, que é sujeita ao equívoco e que também se equivoca, que possibilita que uma prática cultural possa ser outra".
} 
meio de instituições, podemos dizer que é o Estado que também articula a identificação do sujeito à cultura, principalmente por meio do direito. É pelo Direito (o jurídico) que é assegurada a legitimidade do poder do Estado e se reconhecem como legais as medidas tomadas pelo governo para garantir esse poder. Os mecanismos utilizados pelo Estado para assegurar o poder só são possíveis porque o Direito é mantido por instituições, as quais, na leitura althusseriana sobre o marxismo, funcionam como aparelhos ideológicos de Estado (ALTHUSSER, 1985). Dessa forma, o Estado (enquanto aparelho ideológico) funciona por meio de aparelhos ideológicos de Estado - a religião, a escola, a família, o jurídico, o cultural - para que a submissão da classe dominada seja efetivada. Nessa leitura althusseriana, portanto, o Estado funciona como "uma 'máquina' de repressão" (idem, p. 62) por meio da qual o poder é mantido. O Direito, entendemos, é a materialidade pela qual os aparelhos ideológicos de Estado asseguram o funcionamento do Estado. Daí os sujeitos, ao serem individuados pelo Estado, serem sujeitos jurídicos (com direitos e deveres) (HAROCHE, 1992; ORLANDI, 2012) ${ }^{14}$.

É importante observar que Althusser, já na década de 1960, apontava para o gerenciamento da cultura pelo Estado por meio do "Aparelho Ideológico de Estado cultural (Letras, Belas Artes, desportos, etc.)" (1985, p. 44). O trabalho sobre a cultura é uma das formas por meio das quais o Estado funciona, o AIE cultural é uma das instituições que regulam a identificação do sujeito com o Estado. Diferentemente dos Aparelhos repressivos de Estado, que funcionam pela violência, os AIE funcionam pela ideologia. (p. 46). Embora funcionem massivamente pela ideologia, ressalta Althusser, os AIE podem agir pela violência, como, por exemplo, a censura à instância cultural. Ou seja, ainda que não pareça, há um trabalho jurídico sobre a cultura que determina o que pode e deve ser entendido como cultura, ao legitimar e determinar sentidos e excluir outros $^{15}$.

Nesse sentido, para Escobar (1979, p. 185), "categorias totalizadoras e neutras, como as de 'cultura' em geral dissimula a luta de classes no AIE", ao produzir um efeito de universalidade. Dessa forma, se pensarmos no trabalho do Estado sobre a cultura, na sua organização, temos que concordar com Escobar quando ele afirma que

14 Esta e outras discussões que estão presentes podem ser observadas, ainda que de forma incipiente e difusa, em Nascimento, 2015.

${ }^{15}$ Enfatizamos, aqui, o trabalho do jurídico sobre a cultura, mas não podemos deixar de salientar o fato de que ele mesmo, o jurídico, é um fato cultural. 
a "cultura" é bem mais que uma noção, ela é, na verdade, um aparelho cultural que disciplina "bens culturais" diversificados em discursos e práticas culturais que subvencionam os aparelhos escolares, jurídicos, o aparelho familiar, e ajudam a sedimentar tanto as práticas realizadoras do efeito ideológico de sujeito quanto sustentam - em suas razões "civilizatórias" - os rituais de dominação que disciplina por dentro os AIEs.

Por isso, ainda segundo Escobar, "o aparelho de cultura se apresenta como não ideológico porque isso faz parte do discurso mesmo da ideologia dominante como dominante" (p. 187). Para não se cair nesse risco, a saída, para Escobar, é o materialismo histórico, levando em consideração as contradições. Para a Análise de Discurso, o materialismo histórico é fundamental para se pensar o funcionamento do discurso, já que o discurso funciona na/pela contradição. Isso pode ser atestado nos primeiros textos de Pêcheux que, ainda sob o pseudônimo de Thomas Hebert, (HEBERT, 1995, p. 66) reconhece a falta, a existência de contradições e o político como condições sine qua non para falar de uma "ciência da história". Dessa forma, como afirma Rodríguez (2005, p. 20), “o reconhecimento do político é, assim, a única via para a constituição de uma 'ciência da história', desde que não o 'naturalizemos', ao identificá-lo com a organização política das necessidades 'naturais' comuns dos 'grupos humanos"'. É preciso, em relação à cultura, levar em conta essa contradição inerente à política e à história. A construção do consenso é uma tentativa de silenciar a contradição e o olhar da Análise de Discurso sobre as políticas culturais não pode estar cego à contradição.

\section{Ampliação, participação e gestão compartilhada: democratização da cultura e democracia cultural}

Muitas são as formas de se compreender as políticas culturais. Sendo um campo largo, as políticas culturais atualmente se apresentam como uma área interdisciplinar na qual diferentes disciplinas contribuem diferentemente para a sua constituição. Embora não haja um consenso de quando se iniciou as primeiras políticas culturais, a política cultural é definida no Dicionário Crítico de Política Cultural, de Coelho Netto (1997, p. 272), como:

uma ciência da organização das estruturas culturais, a política cultural é entendida habitualmente como programa de intervenções realizadas pelo Estado, instituições civis, entidades privadas ou grupos comunitários com o objetivo de satisfazer as necessidades culturais da população e promover o desenvolvimento de suas representações simbólicas. 
No Brasil, é possível observar mais fortemente o trabalho do Estado sobre a cultura no governo de Getúlio Vargas, na década de 1930, e, posteriormente, na Ditadura Civil-Militar, podemos observar uma sistematização do Estado sobre a cultura. Em 1985, após o fim da Ditadura civil-militar, durante o governo de José Sarney, foi criado o Ministério da Cultura, que passou a não ser mais vinculado ao Ministério de Educação. Posteriormente, foi criada a Lei 7.505, em 02 de junho de 1986, conhecida como Lei Sarney, que buscava impulsionar o campo da produção-cultural por meio de uma Lei de incentivo fiscais para a cultura (CALEBRE, 2007, p. 7). Em 1988, por sua vez, foi promulgada a Constituição de 1988, conhecida como Constituição Cidadã, que apresenta uma grande recorrência da palavra cultura e, pela primeira vez, uma seção específica para tratar desse setor.

A cultura passa reconhecidamente a ser um setor importante para o desenvolvimento do país, principalmente com a criação do Ministério da Cultura, em 1985, e com uma seção específica na Constituição de 1988, que vem sendo alterada no decorrer dos últimos anos por meio de Emendas Constitucionais. Compreender tais mudanças são fundamentais para se compreender o lugar da cultura nas políticas públicas atuais, já que as Emendas Constitucionais, em relação à cultura, iniciaram-se no ano de 2003, época em que houve um aumento considerável de discussões sobre as políticas públicas de cultura na gestão do Ministro Gilberto Gil, que propôs, no primeiro ano de sua gestão, um plano para reestruturar o formato do MinC, alterando as formas de incentivos e abrindo o diálogo com os mais diversos setores interessados com as questões culturais (CALEBRE, 2007, p. 11). A abertura para o diálogo é marcada pela ampliação de políticas de produção e difusão cultural baseadas, sobretudo, na democratização e democracia cultural. Assim, de forma sintetizada, temos ${ }^{16}$ :

\begin{tabular}{|l|l|l|l|}
\hline \multicolumn{1}{|c|}{$\begin{array}{c}\text { Modalidade de } \\
\text { política }\end{array}$} & Conceito de cultura & \multicolumn{1}{c|}{ Objetivo } & \multicolumn{1}{c|}{$\begin{array}{c}\text { Instrumentos de } \\
\text { intervenção }\end{array}$} \\
\hline $\begin{array}{l}\text { Políticas de } \\
\text { democratização } \\
\text { cultural }\end{array}$ & Cultura como belas artes & $\begin{array}{l}\text { Ampliar o acesso à } \\
\text { cultura consagrada }\end{array}$ & $\begin{array}{l}\text { Centros culturais } \\
\text { orientados à difusão, } \\
\text { orquestras públicas com } \\
\text { entradas subsidiadas }\end{array}$ \\
\hline
\end{tabular}

\footnotetext{
16 Tabela retirada do texto $O$ que são as políticas culturais? Uma revisão crítica das modalidades de atuação do Estado no campo da cultura, de Luciana P. B. Lima, Pablo Ortellado e Valmir Barbosa (2013). Nesse mesmo texto, os autores apontam ainda para formas de políticas culturais que precederam as políticas de difusão e produção da cultura, como, por exemplo, as políticas de identidade e de patrimônio e as políticas de proteção à indústria cultural nacional e de economia criativa (2013, p. 10).
} 


\begin{tabular}{|l|l|l|l|}
\hline $\begin{array}{l}\text { Políticas de } \\
\text { democracia cultural }\end{array}$ & $\begin{array}{l}\text { Cultura como modo de } \\
\text { vida }\end{array}$ & $\begin{array}{l}\text { Apoiar a produção } \\
\text { simbólica dos diversos } \\
\text { segmentos sociais }\end{array}$ & $\begin{array}{l}\text { Fomento à cultura } \\
\text { popular e comunitária }\end{array}$ \\
\hline
\end{tabular}

Embora tais modalidades de políticas possam ser observadas ainda antes do ano de 2003, é inegável que a ênfase na democratização da cultura e na democracia cultural se dá a partir desse ano. Nesse sentido, temos uma reestruturação do Ministério da Cultura e o início de uma política cultural voltada para a participação compartilhada. No Art. 215 da Constituição de 1988, há, por meio de Emendas Constitucionais no ano de 2005, o estabelecimento do Plano Nacional de Cultura que visa "ao desenvolvimento cultural do País e à integração do poder público". Com o objetivo de planejar a implementação de políticas públicas a longo prazo (até 2020) para o setor cultural, voltadas principalmente para a proteção e a diversidade cultural, o PNC foi instituído pela Lei 12.243, de 02 de dezembro de 2010. Nesse sentido, conforme consta na página do Ministério da Cultura,

os objetivos do PNC são o fortalecimento institucional e definição de políticas públicas que assegurem o direito constitucional à cultura; a proteção e promoção do patrimônio e da diversidade étnica, artística e cultural; a ampliação do acesso à produção e fruição da cultura em todo o território; a inserção da cultura em modelos sustentáveis de desenvolvimento socioeconômico e o estabelecimento de um sistema público e participativo de gestão, acompanhamento e avaliação das políticas culturais. (Grifo nosso) ${ }^{17}$

É assegurado pelo plano tanto o fortalecimento institucional quanto a construção de políticas públicas voltadas para o setor cultural, que garantiriam o direito constitucional à cultura. Sendo a cultura um direito de todos, o PNC surge para suprir essa necessidade de tornar efetivamente a cultura acessível a todos. Enfatiza-se, com isso, tanto a necessidade de "proteção e promoção do patrimônio e da diversidade étnica, artística e cultural” quanto "a ampliação do acesso à produção e fruição da cultura em todo o território nacional". Há, com isso, um enfoque nos objetos ("no acesso à produção": o produto da cultura), nos sujeitos ("na diversidade") e no espaço ("no patrimônio", "em todo território"). Assim, tanto os sujeitos como os objetos e o espaço que fazem parte da cultura serão inseridos “em modelos sustentáveis de desenvolvimento socioeconômico e o estabelecimento de um sistema público e participativo da gestão, acompanhamento e avaliação das políticas culturais". A cultura é encaixada em um "modelo" de política pública e, dessa forma, é atravessada por diversos discursos: o

\footnotetext{
${ }^{17}$ Retirado da página do Ministério da Cultura, a última atualização tinha sido no 03/07/2014.
} 
discurso da sustentabilidade, da economia e do consenso democrático. A cultura, além de responder ao econômico e à sustentabilidade, passa principalmente a ser construída em torno do consenso construído pela democracia.

Além disso, são três dimensões que são articuladas pelo PNC: "a cultura como expressão simbólica; a cultura como direito de cidadania; a cultura como potencial para o desenvolvimento econômico"18. As três dimensões são dadas como evidências, não há uma problematização e tampouco especificação do que elas seriam. Há, assim, na construção do Plano Nacional de Cultura, a articulação simbólica, cidadã e econômica, sendo ressaltada pela necessidade de "processos de gestão e participação social".

Nesse sentido, na seção "histórico" do PNC: "Plano Nacional de Cultura: principais momentos de uma construção democrática", o título da seção já aponta para essa abertura democrática. É enfatizado o percurso democrático na construção do PNC que constou com 1) "a articulação política social" (desde seminários e conferências, aprovações de medidas na cultura e implantação do Art. 215 na Constituição, em 2005); 2) "informações, diretrizes gerais e debate público" (no período de 2005-2008, realização de seminários e de pesquisa no campo da cultura - IBGE e IPEA); 3) aprovação no Congresso Nacional da Lei do PNC (Lei no 12.323/2010); 4) entre 2011 e 2012, a formulação de metas do PNC, sua elaboração e início de monitoração; 5) entre 20122013, "planos territoriais, setoriais e revisão do PNC" (acompanhamento dos planos estaduais e municipais de cultura e monitoramento do PNC); 6) a partir de 2014, além da continuação do monitoramento do PNC, iniciou-se a discussão de um novo PNC. Por meio de debates, participação nas decisões e monitoramento, produz-se uma ilusão de que as políticas públicas de cultura são construídas por todos, como se fosse resultado de um consenso.

Dessa forma, as próprias metas estabelecidas pelo PNC (53 metas previstas para serem alcançadas até $2020^{19}$ ) "foram estabelecidas por meio da ampla participação da sociedade e gestores públicos". É enfatizado, ainda, que o sucesso do PNC só será possível por meio do envolvimento de todos os federados, pelo Sistema Nacional de Cultura. Além disso, há o monitoramento constante das metas estabelecidas no PNC e qualquer cidadão pode se registrar e receber atualizadas em sua caixa de e-mail o andamento de todas as metas ou personalizá-las, recebendo atualizações de determinada

\footnotetext{
${ }^{18}$ Retirado da página do Ministério da Cultura em 03/07/2016.

${ }^{19}$ Devido ao atual cenário político do país, com a destituição da Presidente Dilma Rousseff, dificilmente essas metas serão alcançadas, visto que elas deixaram de ser prioridades pelo atual governo.
} 
meta que lhe interessa. Tanto a "ampla participação" na construção das metas para o PNC quanto a possibilidade de acompanhar o andamento das metas estabelecidas pelo PNC produzem a ilusão de que há um consenso nas escolhas do que seria melhor para a cultura e, para o sujeito, a ilusão de uma participação efetiva nas políticas públicas de cultura, já que ele ajudou na construção das metas e vem ajudando em sua monitoração ${ }^{20}$.

O Plano Nacional de Cultura é composto de 36 estratégias, 274 ações e 53 metas. Neste trabalho, discutiremos as metas previstas pelo PNC, elas apresentam um planejamento (financeiro, logístico e de objetivos) sobre pontos específicos do setor cultural. De modo geral, as metas ora enfatizam os sujeitos (os agentes produtores de cultura), ora os produtos (os objetos tidos como culturais), ora os espaços (a necessidade de construção e preservação de lugares considerados de cultura), ora os próprios investimentos e ações que não necessariamente apenas incide sobre o sujeito, o objeto ou espaço, mas que visa à melhoria do setor cultural como um todo. Essa regularidade na ênfase nos sujeitos, nos objetos e nas instituições e locais de cultura já nos aponta para algumas considerações importantes acerca da cultura: o processo, o produto e o espaço ${ }^{21}$. Essa memória, que se materializa na textualidade específica dos dicionários de língua portuguesa $^{22}$, atravessa as políticas públicas de cultura do Estado brasileiro na contemporaneidade, produzindo a naturalização na identificação do sujeito com o produto e o espaço. Em tempos de globalização, ainda é a cultura o fator que continua a intervir na identificação dos sujeitos ao Estado-nação.

Devido ao grande número de metas estabelecidas no PNC, selecionamos, para compreendermos o funcionamento do significante "cultura" nas políticas públicas do Estado brasileiro atualmente, quatro metas, a saber:

Meta 3: Cartografia da diversidade das expressões culturais utilizadas em todo o território brasileiro;

\footnotetext{
${ }^{20}$ A monitoração, conforme consta na página do PNC, é feita pelo Ministério da Cultura por meio de "indicadores nacionais, regionais e locais que mostrem a oferta e a demanda por bens, serviços e conteúdos, além de indicadores de nível de trabalho, renda, acesso à cultura, institucionalização, gestão cultural, desenvolvimento econômico-cultural e de implantação sustentável de equipamentos culturais". Tudo isso será transformado em estatística por meio do Sistema Nacional de Informações e Indicadores Culturais (SNIIC) e servirá para avaliação e monitoramento. No entanto, o fato de os sujeitos interessados pelas metas do PNC poderem acompanhar o andamento delas, participarem dos debates e pressionarem por sua efetiva realização produz a ilusão de estarem, de fato, construindo as metas.

${ }^{21}$ Venho insistindo, a partir dos diferentes trabalhos de Carolina Rodríguez-Alcalá, nessa relação entre processo, produto e espaço para se pensar a cultura.

${ }^{22} \mathrm{Na}$ análise do verbete cultura em dicionários de língua portuguesa (NASCIMENTO, 2016), pudemos observar que as definições de cultura são atravessadas por uma memória que leva em consideração o processo, o produto e o espaço.
} 
Meta 4: Política nacional de proteção e valorização dos conhecimentos e expressões das culturas populares e tradicionais implantada;

Meta 8: 110 territórios criativos reconhecidos;

Meta 23: 15 mil Pontos de Cultura em funcionamento, compartilhados entre o Governo Federal, as Unidades Federais e os municípios integrantes do Sistema Nacional de Cultura.

Ao clicar em cada meta, é aberta uma outra página informando sobre o que ela se trata; como ela está sendo medida; o seu histórico (o que foi efetivamente feito); o que está sendo feito para alcançá-la; e, por fim, a situação atual da meta. É possível ainda, na seção comentários, opinar sobre a meta e, na seção "notícias relacionadas", ler sobre temas referentes à meta em questão.

Em relação à meta 3, busca-se "produzir um mapa das expressões culturais e linguagens artísticas de todo o Brasil". Nesse sentido, trata-se de uma cartografia mapeamento - que busca ser totalizador, já que pretende abarcar toda a diversidade de expressões culturais e linguagens artísticas. No tópico que especifica o que seria a Meta 3, temos:

O mapa pretende revelar a diversidade cultural em todo o território nacional, completando o que já existe de mapeamentos, estudos e pesquisas sobre a diversidade cultural brasileira.

A cartografia da diversidade cultural brasileira deve abarcar as especificidades culturais de cada estado e todas as expressões do patrimônio artístico e cultural brasileiro (material e imaterial). Isso significa que serão mapeadas tanto as expressões das linguagens artísticas (teatro, dança, circo, artes visuais, música, entre outras), como aquelas de grupos sociais representantes de vários segmentos de nossa diversidade. Entre esses segmentos estão: povos de terreiro; povos indígenas; ciganos; culturas populares; imigrantes; lésbicas, gays, bissexuais, travestis e transexuais (LGBTs); mulheres; pessoas com deficiência ou transtornos psíquicos; mestres de saberes e fazeres tradicionais; crianças, jovens e idosos.

O levantamento cartográfico será constantemente atualizado no Sistema Nacional de Informações e Indicadores Culturais (SNIIC). (grifo nosso)

Está previsto no PNC que até 02 dezembro de 2020, data prevista para a conclusão das metas do plano, será revelada a diversidade cultural em todo o território nacional: uma diversidade "oculta" que precisa vir à baila. Busca-se, dessa forma, completar mapeamentos e estudos já existentes da diversidade cultural brasileira. Nesse sentido, é preciso abarcar as especificidades (de cada estado) para alcançar a totalidade (todas as expressões do patrimônio artístico e cultural brasileiro, material e imaterial). Na diversidade, busca-se a totalidade (seria uma unidade?) de realizações culturais que tanto 
podem ser material (no sentido de concreto) quanto imaterial (no sentido de não ser concreto $^{23}$. Para abarcar essa totalidade, duas frentes vão sendo construídas: o levantamento das "expressões das linguagens artísticas (teatro, dança, circo, artes visuais, música, entre outras)" e o dos "grupos sociais representantes de vários segmentos de nossa diversidade". Interessa, dessa forma, mapear tanto as expressões quanto os diversos grupos sociais "representantes de vários segmentos de nossa diversidade". Embora se diga que a cartografia abarca a diversidade dos grupos sociais e mapeia a diversidade, $\mathrm{o}$ que temos é uma diversidade construída a partir de uma unidade, e não uma diversidade construída pela diversidade, na diferença. Um efetivo mapeamento da diversidade cultural brasileira não pode partir de uma unidade - o padrão - que define quem são os diferentes - o cultural - a ser mapeado. Apesar de ser uma cartografia, não há a necessidade de se definir a cultura de povos de religião cristã, cultura erudita, homens, heterossexuais ou pessoas consideradas "normais" que definem o padrão de civilização, mas é preciso cartografar o que está mais próximo do diferente, do cultural: os povos de terreiros, povos indígenas, culturas populares (povos/populares: marcas linguísticas que, nesse discurso, vão definindo o cultural em oposição ao civilizado), ciganos, mestre de saberes e fazeres tradicionais etc ${ }^{24}$.

O reconhecimento da diferença se dá a partir de uma unidade e não como princípio primeiro. Por meio de medidas de reconhecimento da diversidade, há um apagamento político-histórico que se dá em torno da fixação de uma democrática pluralidade cultural que se constrói na unidade. Ao reconhecer a diferença na unidade, por meio de políticas de pluralidade cultural que se sustentam, principalmente, em políticas de democracia cultural e de democratização da cultura, nega-se a diferença pela diferença e, com isso, produz-se o reconhecimento da diferença pela unidade. Se aceitarmos a diferença, de fato, como princípio básico, a pergunta que nos fica é: como construir a possibilidade para que a diversidade concreta produza sentido? Para nós que trabalhamos com Análise de Discurso, uma das possibilidades é, pela escuta, abrir condições de produção para que os sentidos se produzam. É por meio da escuta dos discursos que circulam na sociedade que

\footnotetext{
${ }^{23}$ A partir de nosso posicionamento teórico, essa distinção não se sustenta, já que tanto as manifestações ditas materiais quanto as ditas imateriais apresentam uma espessura, uma forma-material.

${ }^{24}$ A palavra povo, no discurso sobre a cultura e nas políticas públicas, parece remeter à cultura, no sentido de primitivo. Esse discurso funciona numa filiação iluminista que constrói uma oposição entre cultura e civilização.
} 
será possível que uma política pública leve em consideração uma tomada de posição que não negue o político, tampouco apague a história ${ }^{25}$.

Por sua vez, em relação à meta 4: "Política nacional de proteção e valorização dos conhecimentos e expressões das culturas populares e tradicionais implantada", o foco recai sobre as culturas populares e tradicionais implantada que passam a ser valorizadas e protegidas por meio de uma ação específica. Nesse sentido, para alcançar esse objetivo, é preciso "ter leis que valorizem e protejam as culturas populares e tradicionais". Essa política de proteção e valorização das culturas populares e tradicionais está de acordo, conforme consta no texto inicial dessa meta, com o que foi aprovado na Convenção sobre a Proteção e a Promoção da Diversidade das Expressões Culturais da Unesco. Em consonância, então, com essa convenção, o Brasil se comprometeu em promover as expressões culturais, o que significa rever algumas leis e criar outras com o intuito de:

proteger tanto os conhecimentos e as expressões culturais tradicionais como os direitos coletivos das populações autoras e detentoras desses conhecimentos. Há o caso, por exemplo, do uso de conhecimentos e expressões culturais tradicionais para fins comerciais. Nessa situação, é preciso garantir que tal uso seja feito com autorização das populações que detêm esses conhecimentos, como, por exemplo, indígenas, quilombolas, ciganos, povos de terreiro e ribeirinhos;

trazer os conhecimentos e expressões culturais populares e tradicionais para dentro da escola. A escola precisa incluir as pessoas reconhecidas pela sua própria comunidade como portadoras de saberes e fazeres das tradições. Essas pessoas, mestres, mestras e praticantes, são a memória viva e afetiva de suas comunidades e das tradições transmitidas de geração em geração. Dar oportunidade para essas pessoas ensinarem na escola formal é uma maneira de valorizar a identidade, ancestralidade e criatividade do povo brasileiro nos processos educativos. Isso também permite aos alunos vivenciar o aprendizado de tradição oral; e

providenciar auxílio financeiro para mestres e mestras dos saberes e fazeres das culturas populares e tradicionais. Assim como todos os cidadãos, pessoas reconhecidas como mestres e mestras precisam ter boas condições de vida. Muitos mestres brasileiros, idosos e jovens, encontram-se em condições de pobreza e risco social. Aplicada a essas pessoas, a proteção social é uma das ações importantes de valorização $e$ salvaguarda das expressões e conhecimentos populares $e$ tradicionais. (grifo nosso)

Dificilmente, alguém duvida que uma política de proteção e preservação dos mais ameaçados culturalmente não seja uma medida importante a ser tomada pelo Estado,

\footnotetext{
${ }^{25}$ Lagazzi (2010, p. 83), ao se referir a Discurso: estrutura ou acontecimento, de Michel Pêcheux, afirma que "uma política pública consequente não pode ser uma política endereçada a todos e a qualquer um. Nos termos de Pêcheux, as políticas públicas precisam constituir tomadas de decisão, 'efeitos de identificação assumidos e não negados', frente às condições materiais de produção".
} 
tendo em vista que o reconhecimento da diversidade cultural perpassa o reconhecimento dos saberes e fazeres das pessoas que vivenciam as mais diversas manifestações tidas como culturais. Nesse sentido, a meta 3 do PNC traz uma série de injunções por meio das quais as expressões, os conhecimentos e os afazeres de culturas populares e tradicionais serão preservados juntamente com os direitos coletivos das populações autoras. E, em caso de fins comerciais, é preciso que se garanta a autorização da população que detém determinados conhecimentos. Uma pergunta um tanto óbvia ${ }^{26}$, mas que nos leva a algumas reflexões, é nos questionar por que, embora o direito já seja assegurado a todos os cidadãos pela Constituição de 1988, é preciso a atualização e a criação de novas leis que garantam esse direito. E, mais do que isso, por que é preciso que algumas manifestações culturais sejam preservadas enquanto outras não apresentam essa necessidade de serem protegidas e preservadas. Podemos pensar que, por nossa Constituição já apresentar uma defasagem histórica (praticamente 30 anos), seria necessário atualizá-la para abarcar a diversidade e proteger as culturas mais vulneráveis, seja por questões históricas, seja pelas atuais ações do mercado que, muitas vezes, descaracterizam a produção cultural. No entanto, não é apenas isso que acontece. Diversos grupos sociais passaram a reivindicar seus direitos de forma mais assídua e isso, nos últimos anos, vem produzindo mudanças na forma em que a Lei era lida.

Nesse sentido, Pfeiffer (2010, p. 98), ao citar Orlandi, afirma que "na relação entre o administrativo e o jurídico, o político funciona como argumento". Isto porque a república (a democracia, a igualdade) funciona na reivindicação de direitos, sendo o jurídico a garantia efetiva de sua realização. Com isso, a autora afirma que "o lugar do político seria o da luta por esses direitos que já se configuram de saída como autoevidentes e iguais para todos. Independentemente de se efetivarem, o espaço de sentido possível do político que configura esses movimentos é o da concessão" (ibidem, grifo da autora). A valorização das expressões e conhecimentos populares e tradicionais e o direito à cultura, já garantido para todo e qualquer sujeito, aparecem para "indígenas, quilombolas, ciganos, povos de terreiro e ribeirinhos" como uma concessão, e não como um direito. Ou seja, aparecem como um "a" mais, uma política de benevolência, e não um direito de fato já garantido. Esse “a” mais só é possível por conta das políticas de

\footnotetext{
${ }^{26}$ A tradução brasileira do título da obra La Verité de la Palice, de Michel Pêcheux, por Semântica e Discurso: uma crítica ao óbvio aponta para essa crítica do óbvio e para a necessidade de sempre nos perguntarmos pelo que nos parece óbvio.
} 
democracia cultural que possibilitaram o reconhecimento de outras expressões culturais que não se limitam às eruditas.

Além disso, "trazer os conhecimentos e expressões culturais populares e tradicionais para dentro da escola" produz necessariamente a didatização desse conhecimento para que ele possa ser "incluído" na (absorvido pela?) escola. Assim, "dar oportunidade para essas pessoas [mestres, mestras e praticantes] ensinarem na escola formal é uma maneira de valorizar a identidade, ancestralidade e criatividade do povo brasileiro nos processos educativos". A oportunidade se dá em função da valorização da identidade, ancestralidade e criatividade do povo brasileiro, e não em função de ser um direito. Com isso, desloca-se a questão do direito de todos a exercer a cultura para a valorização de uma "identidade, ancestralidade e criatividade do povo brasileiro", produzindo a ilusão de que a cultura está fixada em algum lugar no passado e que, mesmo pressupondo a criatividade (mudança), a identidade seria encontrada nos ancestrais, que passam a servir no processo educativo como uma história enrijecida que é preciso conhecer para pertencer a esse povo. Embora esteja se falando do povo brasileiro, há um equívoco sobre quem seria esse povo: o outro, o cultural, o diferente. Essas pessoas são "incluídas" na escola como objetos, não sujeitos. São elas próprias o que restaram dessa ancestralidade, dessa identidade perdida, mas que precisa ser resgatada para efetivamente definirmos quem são os brasileiros. Há, nesse discurso, uma filiação romântica (o retorno ao passado muitas vezes fictício, às raízes da nação), que tem na escola o seu lugar de legitimação e reprodução.

Dentre as 53 metas estabelecidas no Plano Nacional de Cultura, é interessante observar que uma parte delas se preocupa tanto com o espaço institucional, que garante melhorias no âmbito da cultura, quanto com os espaços culturais em si. Nas últimas décadas, assim, pudemos observar o aumento tanto de centros culturais quanto de espaços para promoção da cultura, além de um amplo esforço de tornar lugares usualmente tidos como culturais - as bibliotecas e os museus por exemplo - ainda mais efetivos e atrativos para o público. Há, nesse sentido, metas que estabelecem "100 mil escolas públicas de Educação Básica desenvolvendo permanentes atividades de arte e cultura (Meta 14)"; “37\% dos municípios brasileiros com cineclube (Meta 30); "Municípios brasileiros com algum tipo de instituição ou equipamento cultural, entre museu, teatro ou sala de espetáculo, arquivo público ou centro de documentação, cinema e centro cultural” (Meta 31); “100\% dos municípios brasileiros com ao menos uma biblioteca pública em funcionamento" (Meta 32), entre outras. Para compreender essa relação como o espaço, 
neste trabalho, optamos por analisar duas metas que incidem sobre o espaço: "110 territórios criativos reconhecidos" (Meta 8) e "15 mil Pontos de Cultura em funcionamento, compartilhados entre o Governo Federal, as Unidades Federais e os municípios integrantes do Sistema Nacional de Cultura” (Meta 23). Assim, temos:

Territórios criativos são bairros, cidades ou regiões que apresentam potenciais culturais criativos capazes de promover o desenvolvimento integral e sustentável, aliando preservação e promoção de seus valores culturais e ambientais.

(...) Como explicado na Meta 7, a economia criativa é um setor estratégico e dinâmico, tanto do ponto de vista econômico como social. Suas atividades geram trabalho, emprego, renda e inclusão social.

Um território será legitimado pelo Ministério da Cultura (MinC) como território criativo por meio de uma chancela (selo). Com isso, poderá ser criado um sistema de governança com a participação do poder público e da sociedade civil. A partir desse reconhecimento, o MinC repassará recursos para a formulação de planos de desenvolvimento que tenham a economia criativa como estratégia. (META 8, grifo nosso)

Pontos de Cultura são espaços que desenvolvem ações socioculturais, com o apoio do Ministério da Cultura (MinC). Em geral, esses espaços estão localizados em comunidades à margem dos circuitos culturais e artísticos convencionais.

Criado pelo programa Cultura Viva do MinC, o Ponto de Cultura tem como característica a gestão compartilhada entre poder público (municipal, estadual ou federal) e a comunidade. Como pode estar instalado em uma casa ou em um grande centro cultural, ele é o ponto de partida para outras iniciativas, que se multiplicam com novos agentes e parceiros quando se juntam às ações iniciais. Assim, é possível ampliar o espaço de atuação para a escola mais próxima, o salão da igreja, a sede da sociedade de amigos do bairro ou a garagem de algum voluntário. A ideia é que o Ponto seja o centro de uma teia que se espalha por toda a comunidade.

Os Pontos de Cultura foram criados para estimular o acesso à cultura, promover a cidadania e valorizar as manifestações culturais locais. A comunidade se envolve e os cidadãos ficam mais motivados para criar, participar e reinterpretar a cultura. (META 23)

Legislar, regulamentar e legitimar o território são os objetivos, de maneira geral, das metas 8 e 23. Trata-se, portanto, de reconhecer o potencial cultural de uma região e estimular espaços para que se desenvolvam ações socioculturais. Além de possibilitar aos sujeitos que ele vivencie e produza cultura, os espaços funcionam na produção de sentimentos, sentidos, em relação ao local, à sua cultura ${ }^{27}$. É ao reconhecer-se como parte

\footnotetext{
${ }^{27}$ Orlandi (2011, p. 25) afirma que "questões de pertencimento, de território e territorialidade: o sentir-se em casa, como parte dos processos de identificação, agora com a cidade, com o país, com a Nação, com o Estado. Sentido (observem que já não estou dizendo 'sentimentos', mas sentidos)".
} 
do espaço que o sujeito significa-se e produz sentidos. Essa relação material, para nós, é condição para que o sujeito se signifique. Assim, o trabalho do Estado sobre o espaço, ao mapear tanto os territórios quanto os pontos de cultura, dando-lhes um selo, vai produzindo amarras, pelo local, no sujeito a partir das quais ele não vai podendo dizer e sentir outra coisa a não ser pertencente a esse local, parte de um todo: o Estado-nação. $\mathrm{O}$ território criativo e os Pontos de Cultura, nesse sentido, são pontos de partida que vão se espalhar e irradiar "cultura" por toda a sociedade, seja atingido os que estão considerados à margem, seja por meio de pontos que se espalham e atingem um maior número de sujeitos.

Como já discutimos, na definição das políticas públicas de cultura na contemporaneidade, há o atravessamento tanto do discurso econômico quanto do discurso da sustentabilidade. Para ser reconhecido enquanto um território cultural, é preciso que o local tenha potencial criativo que lhe possibilite o desenvolvimento da economia criativa. Isso significa que a preservação do local está relacionada ao desenvolvimento econômico e criativo do espaço, o que possibilitará a geração de "trabalho, emprego, renda e inclusão social". A cultura, nesse sentido, é trabalhada pelo Estado por meio de seu potencial econômico, ao gerar trabalho e renda, ela inclui o sujeito na sociedade. No entanto, a pergunta que nos fica é: sendo a cultura a possibilidade de identificação do sujeito ao Estado, como poderíamos falar de inclusão? Se a cultura já é uma das condições para que o sujeito se identifique ao Estado, não poderíamos, pois, falar de sujeitos fora, já que, pelos processos imaginários em torno da cultura, o sujeito já se subjetiva dentro, pertencendo a uma cultura e a um espaço, e não a outros.

Contudo, na esteira dos trabalhos de Orlandi (2010a, p. 7), é se interrogando pelo par inclusão/exclusão que a autora chega à conclusão de que "a representação das relações sociais contemporâneas é a segregação, ou seja, ou os sujeitos estão dentro ou fora do campo da sociabilidade”. Nesse sentido, “a produção do consenso está sustentada em uma concepção de vínculo social que produz a segregação, em um complexo processo em que as noções de cidade, de cidadão, de cidadania, de indivíduo, de sociedade são (re) significadas" (ibidem, grifo da autora). A essas noções elencadas pela autora, acrescentamos a noção de cultura que é fundamental para a construção do vínculo social. O Estado, ao incluir o sujeito no espaço urbano, se utiliza de políticas públicas, dentre elas as que são voltadas para a cultura, que funcionam a partir de um imaginário de democracia em que todos teriam direitos iguais. As políticas públicas, ao produzir um consenso, uma unidade, nega a diferença e se encaminha para a segregação. 
Tanto no Território Criativo quanto nos Pontos de Cultura temos a participação da sociedade na gestão da cultura, naquele é afirmado que "poderá ser criado um sistema de governança com a participação do poder público e da sociedade civil", enquanto neste se "tem como característica a gestão compartilhada entre poder público (municipal, estadual ou federal) e a comunidade". Tanto por meio da participação da sociedade civil quanto por meio de uma gestão compartilhada com a comunidade se produz a ilusão de que todos estão participando da construção da cultura, numa perfeita assimetria, quando, de fato, é o Estado que chancela quem tem ou não o direito de ser considerado um Território Criativo ou um Ponto de Cultura. A participação da sociedade nas políticas públicas de cultura, desse modo, funciona na construção de uma administração consensual que apaga o litígio, ao produzir achatamento nas relações de força na sociedade como se a todos fossem assegurados igualmente o direito de "participar e reinterpretar a cultura".

\section{Considerações finais}

Embora haja muitos trabalhos na Sociologia e na Antropologia que discutam as definições de cultura e suas mudanças ao longo da história do Ocidente, é importante buscar compreender a constituição histórica dos sentidos em torno da palavra "cultura" na sua relação com os sujeitos e o espaço, sem negar a necessidade de um estudo que busque compreender o funcionamento dessa palavra hoje nas políticas públicas. $\mathrm{O}$ trabalho político do Estado sobre a cultura produz mudanças na forma com que os sujeitos se relacionam entre si e com o Estado. Isto porque são as políticas públicas de cultura, entre outras, as responsáveis por construir lugares de identificação a partir dos quais os sujeitos, pela homogeneização e equação da cultura à identidade nacional, se reconhecem como parte de um mesmo Estado nacional.

Em diferentes momentos da história brasileira, a cultura foi tomada de formas distintas pelos governos que estavam no poder. No entanto, embora apresentassem interesses diferentes, é importante observar que, independentemente de governo, a cultura é tomada pelo Estado como uma unidade formal, já que se produz uma unidade no interior de diferentes configurações de culturas, ou seja, a pluralidade é organizada por um discurso do Estado que busca homogeneizar a cultura. Há, portanto, uma relação tensa e contraditória entre a unidade formal e a diversidade concreta das culturas. Assim, enquanto é possível observarmos forças centrífugas, as diferentes culturas em 
funcionamento, forças centrípetas trabalham na formalização e homogeneização da cultura, ao determinar os sentidos de cultura, preservar determinados monumentos e relegar outros ao esquecimento, ou seja, ao produzir uma memória a ser lembrada, enquanto outras serão esquecidas.

Desse modo, o esforço das políticas públicas de cultura de normatizar o que é cultura e de inclui-la no dia-a-dia dos sujeitos e em diferentes instituições (na escola, por exemplo) faz parte dos processos de identificação dos sujeitos com o espaço nacional, o Estado, e as políticas de democratização cultura e democracia cultural não estão alheias a isso. Apoiados na opinião pública, segundo Orlandi (2010a, p. 6-7), a produção do consenso "é assim considerada um ideal para solucionar satisfatoriamente os conflitos sociais, pela instituição de um 'nós' coletivo sobre o qual desenhar políticas que atendam às aspirações e sentimentos compartilhados pelos indivíduos e grupos que integram a sociedade". Nesse sentido, a construção do consenso - por meio da gestão compartilhada, participativa, regime de colaboração, democratização dos processos decisórios - é uma tentativa de silenciar a contradição, a diferença, ao administrar a diferença em prol de uma suposta unidade consensual.

\section{Referências}

ALTHUSSER, Louis. Aparelhos ideológicos de Estado. 2. ed. Trad. de Valter José Evangelista e Maria Laura Viveiros de Castro. Rio de Janeiro: Graal, 1985.

CALEBRE, Lia. Políticas Culturais no Brasil: balanço e perspectivas. In: Anais do III ENECULT: Terceiro Encontro de Estudos Multidisciplinares em Cultura. UFBA: Salvador, 2007, p. 1-18.

COELHO Netto, José Texeira. Dicionário crítico de política cultural: cultura e imaginário. São Paulo: Editora Iluminuras LTDA, 1997.

DE NARDI, Fabiele Stockmans; BALZAN, Fabíola P. Relações entre cultura e ensino: um olhar sobre as políticas públicas para formação de professores. In: Organon (UFRGS), v. 24, 2010, p. 87-102.

DESCENDRE, Romain. Aux origines de l'"État": langage et institutionnalisation de la domination. In: Eni Orlandi (org.). Linguagem, Sociedade, Políticas, Univás - RG Editores, 2014, p.15-27.

DORNELES, Elizabeth. A ordem da cultura. In: Maria Cristina Leandro Ferreira. (Org.). Oficina de Análise do Discurso: conceitos em movimento. 1 ed. Campinas - SP: Pontes Editores, 2015, p. 179-194.

ESCOBAR, Carlos Henrique. Da categoria cultura: do aparelho cultural do Estado. In: FELIX, M. et al. Encontros com a civilização brasileira, v. 16. Rio de Janeiro: Civilização brasileira, 1979, p. 183-214. 
ESTEVES, Phellipe Marcel S. Rumo a uma noção de formação cultura na AD. In: Anais do V SEAD. O acontecimento do discurso: filiação e rupturas. Porto Alegre: UFRGS, 2011 .

O que se pode e deve comer: uma leitura discursiva sobre sujeito e alimentação nas enciclopédias brasileiras (1863 - 1973). Tese de doutorado da Universidade Federal Fluminense, Instituto de Letras, 2014.

HAROCHE, Claudine. Querer Dizer, Fazer Dizer. São Paulo: Hucitec, 1992.

HEBERT, Thomas. [PÊCHEUX, M.]. Observações para uma teoria geral das ideologias. In. RUA - Revista do Núcleo de Desenvolvimento da Criatividade da Unicamp. Nucredi: Unicamp, n. 1, 1995.

LAGAZZI, Suzy. O confronto político urbano administrado na instância jurídica. In: Discurso e políticas públicas e urbanas: a fabricação do consenso. Campinas, Editora RG, 2010, p. 75-84.

LEANDRO-FERREIRA, Maria Cristina. O lugar social e da cultura numa dimensão discursiva. In: INDURSKY, F.; MITTIMANN; S. LEANDRO-FERREIRAM M. C. Memória e história na/da Análise de Discurso (Org.). Campinas, SP: Mercados das Letras, 2011, p. 55-66.

LIMA, Luciana; ORTELLADO, Pablo; SOUZA, Valmir. O que são as políticas culturais? Uma revisão crítica das modalidades de atuação do Estado no campo da cultura. In: Anais do IV Seminário Internacional de Políticas Culturais, 2013, p. 1-17.

MARIANI, Bethania. Uma proposta de arquivo sobre o sujeito da cidade do Rio de Janeiro: Uma pesquisa sobre o discurso em farrapos. p. 43-63. In: Di Renzo, Ana; MOTTA, A. L. A. rodrigues; OLIVEIRA, Tânia Pitombo de. (Org.). Linguagem história e memória: discursos em movimento. 01 ed. Campinas: Pontes, 2011, v. 1, p. 43-64.

MINISTÉRIO DA CULTURA - BRASIL. Plano Nacional de Cultura. Disponível em: http://www.cultura.gov.br/plano-nacional-cultura-pnc-. Acesso em 26/06/2017.

NASCIMENTO, Felipe Augusto Santana do. Entre as fronteiras da terra prometida: os trabalhos da memória e da história na representação dos brasiguaios. Dissertação de Mestrado em Letras, UFPE. Recife: [s. n], 2015.

O verbete cultura: apontamentos sobre a relação entre cultura e Estado (nacional). In: ORLANDI, Eni et al. Anais do Enelin 2015. Pouso Alegre: Univás, 2016, p. 234-240.

ORLANDI, Eni. Terra à vista. Discurso do confronto: velho e novo mundo. 2 ed. Campinas: Editora da Unicamp, 2008.

Apresentação. In: Discurso e políticas públicas e urbanas: a fabricação do consenso. Campinas, Editora RG, 2010a, p. 5-10.

Os sentidos de uma estátua: Fernão Dias, individuação e identidade pousoalegrense. In: . (Org.). Discurso, espaço, Memória - caminhos da identidade no sul de Minas. Campinas: RG, 2011, p. 13-34.

PÊCHEUX, MICHEL. [1975]. Semântica e Discurso: uma crítica à afirmação do óbvio. 4. ed. Campinas: UNICAMP, 2009.

. Ler o arquivo hoje. In. ORLANDI, E. P. (Org.). Gesto de leitura. Campinas:

Editora da Unicamp, 2010, p. 49-60 
Discurso: estrutura ou acontecimento. Trad. Eni Orlandi. 6 ed. Campinas: Pontes editores, 2012.

PFEIFFER, Claudia. Políticas públicas de ensino. In: Discurso e políticas públicas e urbanas: a fabricação do consenso. Campinas, Editora RG, 2010, p. 85-100.

RODRÍGUEZ, Carolina. Língua, nação e nacionalismo: um estudo sobre o guarani no Paraguai. Tese de doutorado - Universidade Estadual de Campinas, Instituto de Estudos da linguagem. Campinas, SP: [s. n.], 2000.

. Em torno de observações para uma teoria geral das ideologias de Thomas Herbert. In. Estudos da Linguagem, Vitória da Conquista, n. 1, jun 2005, p. 15-21.

RODRÍGUEZ-ALCALÁ, Carolina. Entre o espaço e seus habitantes. In: ORLANDI, Eni. Por uma enciclopédia da cidade. Campinas, SP: Pontes/Laberub/Unicam, 2003, p. 6584.

Da religião à cultura. In: Anais da ANPOLL, 2004.

- Políticas públicas de direito à língua e consenso etnocultural: uma reflexão crítica. In: Discurso e políticas públicas e urbanas: a fabricação do consenso. Campinas, Editora RG, 2010, p. 127-158.

. Discurso e cidade: a linguagem e a construção da "evidência do mundo". In: RODRIGUES, E. A.; SANTOS, G. L. CASTELLO BRANCO, L. K. A. (orgs.) Análise de Discurso no Brasil: pensando o impensado sempre. Uma homenagem a Eni Orlandi. Campinas: Editora RG, 2011a, p. 243-258. 


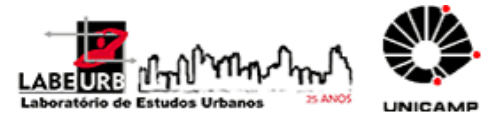

\section{Para citar essa obra:}

NASCIMENTO, Felipe Augusto Santana do. Ler a cultura hoje: a construção do consenso nas políticas culturais do Estado brasileiro. In: RUA [online]. $n^{\circ}$. 23. Volume 2, p. 311 - 334 - e-ISSN 2179-9911 - Novembro/2017. Consultada no Portal Labeurb - Revista do Laboratório de Estudos Urbanos do Núcleo de Desenvolvimento da Criatividade.

http://www.labeurb.unicamp.br/rua/

Capa: Disponível em: http://www.achabrasilia.com/wp-content/uploads/2010/11/PLANO.jpg

Laboratório de Estudos Urbanos - LABEURB

Núcleo de Desenvolvimento da Criatividade - NUDECRI

Universidade Estadual de Campinas - UNICAMP

http://www.labeurb.unicamp.br/

\section{Endereço:}

LABEURB - LABORATÓRIO DE ESTUDOS URBANOS

UNICAMP/COCEN / NUDECRI

CAIXA POSTAL 6166

Campinas/SP - Brasil

CEP 13083-892

Fone/ Fax: (19) 3521-7900

Contato: http://www.labeurb.unicamp.br/contato 